\title{
NATURAL RESOURCES EFFECTIVE MANAGEMENT AS SPHERE OF SOCIO- ECONOMIC DEVELOPMENT AND RESEARCH AREA
}

\author{
Prilukov A.N.* , Candidate of Sociological Sciences, Associate Professor \\ Sekisov G.V., Doctor of Technical Sciences, Professor \\ Litvintsev V.S., Doctor of Technical Sciences, Associate Professor \\ Mining Institute of Russian Academy of Sciences, Khabarovsk, Russia \\ *E-mail: a prilukov@mail.ru
}

\begin{abstract}
In the article some peculiarities and crucial turning points in natural resources exploration, harnessing, and deployment are overviewed. Alongside with agricultural production, minerals mining and utilization provide humankind with vital material means of its existence. Both productive spheres develop much in parallel and are serving as akin subjects for socioeconomic sciences. Progress and some outcomes of scientific and practical developments that took place within these spheres, particularly concerning mineral resources management, are traced from the first quarter of twentieth century up to our days.
\end{abstract}

\section{KEY WORDS}

Natural resources, economics of exhaustible resources, effective mineral resources management, universal and institutional mineral husbandry conceptions.

Exploration, mining, processing, marketing, and industrial application of mineral resources (MRs), along with agriculture related similar activities, represent essential parts of the World and many national economies. In the article they are viewed as congeneric and interconnected economic spheres, based on natural resources industrial acquirement and productive utilization, generally called natural resources management (NRM) [1].

Specifically, modern development direction of the World's industrial mining sector is overviewed, which consists in the sector's economic, technological, commercial, and informational processes management upgrading, thus enhancing the sector's overall functioning. Emergence and onward movement of this theoretic and applied direction, methodologically based on above mentioned processes combined and systematized handling, are traced from the time of Great Depression, which engulfed many countries and severely hampered both industrial and agricultural production. At that time the so called Economics of Exhaustible Resources research movement popped-up, aimed at counteracting and mitigating the economic crisis burdens and chores. Several decades later the notion of Mineral Resources Management (MRM) has emerged. In the article it is dealt with as multi-component complex of closely interconnected processes, engaged in geologic exploration, mining, processing, marketing, and eventual industrial application of mineral raw as well as profoundly processed materials.

These MRM characteristics are illustrated by examples of widely spread activities, aimed at designing and implementing of high-tech Effective Mineral Resources Management (EMRM) systems that are being created to fulfill the tasks of diverse information gathering, its processing, formalized and essential analyses conducting, predictions formulating, administrative decisions adopting, automated control and management performing with respect to technologic and other processes and risks. Particular scholars' and countries' roles are briefly overviewed with respect to EMRM ideas development and appropriate scientific-and-applied conception varieties creation.

Particular attention is devoted to Poland and Russia. Poland's role is illustrated mostly by its popular Gospodarka Surowcami Mineralnymi journal's enduring publication, while Russia's achievements are specified by two Mineral Husbandry Conceptions - the Universal and Institutional ones, - which were at appropriate moment put forward, are persistently being developed, and in due time undergo upgrading. 
Historic benchmarks. Industrial and commercial activities, involved in geologic exploration, mining, and large scale utilization of MRs, as well as research efforts, engulfing nowadays most MR-endowed countries and directed toward efficiency enhancement of interconnected processes, which in their complex entirety comprise these activities, are now most often referred to as Mineral Resources Management (MRM). According to our approximate estimations, in English speaking countries this term appeared in the XX century's third quarter. In any case, as early as in 1976 the state of MRM activity in developing countries has been discussed at the Sidney geologic symposium [2].

One of the precursors of notions, symbolized by the term MRM, is reasonably assumed to be the scientific direction labeled as Economics of Exhaustible Resources. It is worth to note that exhaustible happen to be not only minerals but also major agrarian resources, such as arable land, water sources, fertilizers etc. Widely esteemed forefather of this research direction considered to have been US economist, and also specialist in mathematical statistics and functional analysis Harold Hotelling, which published article of the same title [3] that has not yet lost its former popularity. In this research direction Robert Solow, Joseph Stiglitz, Robert Pindyck, Jon Conrad, Thomas Teisberg, and other well-known authors took part.

Research in this direction now goes on, engulfing in its rows new adherents. According to tradition its successors concentrate their attention on problems of raising the economic effectiveness and commercial output that characterize operations connected with acquiring and marketing of nonrenewable resources, including MRs. However, the participants of the prolonged research, anxious with its low analytical and prognostic effectiveness, lastly are frequently casting their glances also at political-and-economic, social, and ecologic aspects of minerals mining and utilization, at the same time preserving intact traditional adherence to mathematical-statistical and functional analyses.

Approximately in 3rd quarter of previous century in the world industrial-economic and entrepreneurial communities awareness sprung up of the fact that besides nonrenewability the MRs also possess some other characteristics, making them unique kind of industrial, commercial, and consumer assets. Firstly, MRs mining is conducive to penetration into all Earth spheres, accessible according to modern level of technical development, and on all continents except Antarctica, where such activities are now forbidden by existing international agreements. Secondly, MRs mining, processing, and industrial consumption up to now reached such enormous and continuing to grow up amounts that they are hardly can be equally challenged by any other human activity. Thirdly, concerning their ecologic consequences, the MRs mining and processing are at least comparable and in many cases considerably overwhelm negative outcomes from other forms of activity. Lastly, mining, processing, marketing, and logistic operations with MRs, as in no other activity, in recent decades are becoming the realm of powerful and diversified transnational corporations, which merely by their presence dilute boundaries between countries and at the same time sharpen and widen competitive struggle for acquiring and disposing of mineral resources.

As a result of mineral resources isolation as objects that require particular approach in studying and management, new direction of research and industrial activity, known nowadays as Mineral Resources Management, has emerged. One of its benchmarking events was the start of publication in 1985 of novel Polish journal Gospodarka Surowcami Mineralnymi (Mineral Resources Management), which up to now remains the only worldwide periodic edition, named precisely by generally accepted term. Meaningful and perhaps nonrandom coincidence is seen also in publication at the same time in Moscow publishing house Nedra of joint Russian and Hungarian authors' monograph [4], in which for the first time in Russian scientific literature the term "mineralopol'zovaniye» (Mineral Husbandry $M H$ ) was used, equivalent in its scope and many content aspects to English term MRM. Taking this into account, in subsequent text we will use unified set of terms, replacing Russian terms Mineral Husbandry and Rational Mineral Husbandry ( $M H$ and $R M H$ ) by their English closely related analogs MRM and recently adopted Effective Mineral Resources Management (EMRM).

Simultaneously with Russia's decision in early 1990th to reorient her further socio- 
economic development toward market economic model, an idea has been formulated in FEB RAS Mining Institute of specific problem area allocation for scientific studies, denoted initially as Rational Mineral Husbandry. Based on this idea, subsequent creation of conceptions, theories, and ultimately wide scientific direction, which was supposed to incorporate great numbers of complex structured parts, were proposed. During short time this idea has been vigorously argued and persistently advertised. However, as a result of following substantive criticism it was appropriately revised and presently continues to develop in refurbished form. Besides, after critical reassessment of primarily unjustifiably abstract and methodically not irreproachable ideas, the initial research area was subdivided into two competing and at the same time mutually complementary directions.

Within initially fundamentally holistic Universal direction, aimed at all subject aspects ultimately wide coverage, MRM was proposed to be dealt with as planet-wide phenomenon that penetrates different social life spheres and is interacting with many areas of science, techniques, and human activities as a whole. In alternate moderately reductionist Institutional direction an option was chosen of research subject precise specification and its problematics restriction to MRM institutional and organizational structure, including its functioning and development regularities, characteristic to different social and economic environment.

Up to now neither of the two mentioned research directions succeeded in acquiring sufficient amounts of followers and at affirming themselves in statuses of theoretical and applied conceptions being acknowledged by the world scientific community. Significantly, this is explained by extremely rare publications occurrences, such as [5-7], covering ideas of research, its progress and results in popular foreign editions. Nevertheless, notions and ideas being substantiated in these research directions are ever more frequently receive practical confirmation and are embodied in modern studies, extensively carried out in theoretical, industrial, and commercial areas.

Geography of Effective Mineral Resources Management ideas dissemination. Recently EMRM ideas, which play systematizing and organizing role in diverse activities associated with MRs mining and utilization, dashingly gain popularity. According to information, circulating in Internet, during 2 to 3 recent years the number of term MRM occurrences in names and profile descriptions of industrial, research, and consulting firms, managing divisions of state and municipal organizations, territorial, national, and international projects, aimed at enhancing appropriate territories' natural and industrial potentials effective utilization, rose approximately ten-fold. This coincide with appearance of new divisions, laboratories, firms and with massive reorientation of existing ones, formerly engaged predominantly in mining enterprises informational servicing, to complex multy-aspect consulting, and also to appropriate projects designing and realization, aimed at functional effectiveness enhancing of MRM-objects, belonging to different organizational levels. Presently such companies and associations equally successfully function both in big economically developed as well as in small developing countries and regions of the World (Table 1).

Functioning of mentioned above as well as many other MRM companies and associations is rarely confined to places of their headquarters registration or localization and in total is spreading over vast majority of countries and regions where MRs are in industrial amounts mined and/or industrially utilized. Besides, in many countries, possessing industrially feasible reserves of natural MRs, there are public or private organizations and their divisions that perform various functions of mineral resources management at state, regional, and municipal levels.

Because of wide internationalization of MRM activities, geographic tracing of appropriate ideas is not a trivial task. In Africa, for example, according to [8] MRM-ideas are actively developing beginning from 1996. By the way, first steps in this direction were made, as well as in other World regions, by the companies based in Canada and some other developed Western countries.

Poland, former USSR, and Hungary, as indicated above, joined the improvised club of MRM-ideas followers in 1985. However, as opposed to Poland, in the former USSR and its legal successor Russia operations with MRs, according to tradition, originated as early as in 
20-30th years of $X X$ century, up to now are invariably, although not quite appropriately, remain associated with the underground space utilization, labeled as "nedropol'zovanie» subsoil husbandry (SH). On the federal level there is government agency "Rosnedra» (Russian Subsoil), upon which, together with its regional divisions, tasks are assigned concerning subsoil management on appropriate organizational levels. Research organizations and educational institutions are functioning, whose founding documents and educational programs envisage studying the $\mathrm{SH}$ problems, including among others MRs mining. Periodicals are published, specialized in $\mathrm{SH}$ problems tackling, including those of mining industry, viewed as particular part of subsoil usage.

Table 1 - Consulting, designing, and implementation companies and associations that elaborate and realize versions of EMRM conceptions

\begin{tabular}{|l|l|}
\hline \multicolumn{1}{|c|}{ Company, association } & \multicolumn{1}{|c|}{ Headquarters localization } \\
\hline BMG Consulting Pty Ltd & Australia: Melbourne \\
\hline Continental Resource Management Pty Ltd & Australia: Belmont (WA) \\
\hline Exxpleo Pty Ltd & South Africa: Pretoria, Gauteng \\
\hline Gemecs Pty Ltd. & South Africa: Blackheath \\
\hline Geoscience Ireland & Ireland: Dublin \\
\hline Gismatix Inc & Canada: Ottawa \\
\hline Global Minerals Engineering LLC & USA, Hibbing (Minnesota) \\
\hline HCL Technologies & India: Noida \\
\hline Implats (Impala Platinum Holdings Ltd.) & South Africa: Sandton, Gauteng \\
\hline Kimopax Pty Ltd. & South Africa: Midrand, Gauteng \\
\hline Mineral Resource Management Inc. & USA: Morgantown (West Virginia) \\
\hline MineRP & South Africa: Centurion \\
\hline MINROM & South Africa: Centurion \& Windhoek \\
\hline Minxcon Group & South Africa: Gauteng \\
\hline Prysm Resources Pty Ltd & South Africa: Olifantsfontein \\
\hline Randgold Resources. & Channel Islands: Jersey \\
\hline SAP & Germany: Walldorf \\
\hline SIMCO & Colombia: Bogota \\
\hline SRK Consulting Australia & Australia: Brisbane \\
\hline SRK Consulting & South Africa: Johannesburg \\
\hline SRK Consulting (UK) Ltd. & UK: Cardiff \\
\hline Terra-Tec (Barnstone Corporate Services) & South Africa: Pretoria, Centurion \\
\hline Z Star Mineral Resource Consultants Pty Ltd & South Africa: Cape Town \\
\hline
\end{tabular}

Up to now the only Russian specialized periodical, according to its title devoted exactly to MRM problems, is «Mineral Resources of Russia. Economics \& Management» journal, published by "Geoinform» publishing house. Paradoxically, but the terms MRM or its Russian equivalent $\mathrm{MH}$ appear on pages of this periodical only episodically, as for example in [9], whereas number of the term "subsoil husbandry» appearance cases is difficult to enumerate. Similar situation manifests itself in popular Russian periodicals «Mining Journal», «News of the Higher Institutions. Mining Journal», "Mining Informational and Analytical Bulletin», "Subsoil Husbandry - XXI Century» and some others, which publish articles on SH subject area much willingly than on MRM [10-13].

Key ideas of Mineral Resources Management and their incarnation in scientific conceptions and in practice. As was already mentioned, Russian term Mineral Husbandry (close analog of MRM) appeared first in [4]. Unfortunately, newly introduced term was not specified in this publication. Besides, its key notion "rational utilization and protection of natural resources», kindred to EMRM, was allotted there with several different meanings. Presumably, because of that novel publication [4] for a long time remained almost unnoticed.

With regard to the Russian economy's market reforms, started in early 1990s, full-scale definitions of the terms $\mathrm{MH}$ and $\mathrm{RMH}$ were given in publications of Sekisov G.V., Prilukov A.N. and their co-authors. For example, in [12, p.18,24] the term MRU was formulated as the object that in its major manifestations behaves simultaneously "as industrial system, specific system of adjacent scientific areas and mining sciences, economics, theoretical engineering, and other interacting sciences; hierarchical system of 
scientific-and-technical problems; complex of adjacent educational disciplines; social-andeconomic system; ecological system; legal system». Object, denoted by the term "Rational $M H »(R M H)$ was described there as "highly complicated (according to its contents), voluminous (by its scale), and dynamic (by its functioning) system of public-and-industrial interaction of mankind with the Earth's mineral materials and various natural mineral objects» $[12$, p.18].

Subsequently, above-cited definitions, which describe MRM and EMRM as essentially multi-system objects, were reappraised by their author as irrational, because that led to spreading these objects' boundaries and complicated their positioning in sciences classifications, which in its turn substantially hampered rendering these objects as real, selfreliant and developing systems [10].

In [14; 15, p.18] «Mineral Husbandry» (MRM) notion was rendered as terminological category that denominates the aggregate "of processes and/or human activities, viewed in their interaction and interdependence, and pertaining to geologic search of mineral deposits, their development, raw materials extraction and processing, as well as mineral products marketing and their primary industrial utilization». In subsequent author's publications the term's detailed definitions were formulated, which principally not differ from the cited one but contain more extensive enumerations of processes and activities, enveloped by the term.

Among major theoretic, methodological, and applied results, obtained within conceptions, which are still being developed, following may be named:

- ascertaining the objective system essence of modern MRM processes, which engulf entire economic cycle «mining of mineral resources - their commercial realization eventual industrial utilization»;

- choice substantiating of complex methodology and multi-discipline approach to MRM processes studying and optimization;

- replenishment, concretization, and refinement of terminological thesauruses, used in new areas of knowledge and practical activities;

- designing of considerable amounts of classification schemes, which extend knowledge concerning MRM-objects by reflecting their substantial composition, aggregate state, peculiarities of localization, and variations of industrial utilization technologies;

- creation of theoretic generalized schematic models, reflecting stages of MRM technologic processes and character of tasks being realized at every industrial production stage;

- creation of formalized models, depicting institutional, organizational, and functional structures of economic MR-sectors, their reformation and restructuring processes;

- revelation of major factors and tendencies, influencing MRM processes, identification their multi-level structure and manifestation peculiarities at the world, national, and regional levels;

- upgrading and developing methodologies for strategizing and strategic targeting with respect to MRM-objects, belonging to various organizational levels;

- development and enhancement of formal-logic and mathematical methods, as well as computer software, suitable for employment in currently dealt with and adjacent research areas.

Enumerated results are reflected in dozens of authors' publications and are currently used as learning aids in educational studies of mining disciplines. One of them is proposed and being developed educational discipline «Rational Mineral Husbandry». Besides, in the course of described investigations multi-page informational, analytical, and recommendation materials were worked out and at different moments handed over to federal and regional organs of MRs management.

According to definition formulated in 2002 by $A$. Macfarlane «MRM is an integrated activity which identifies, evaluates and provides an optimal extraction plan of the mineral resource, to produce a quality product which satisfies the business objectives of the company, and the requirements of the customer, in a dynamic environment. It performs an 
audit and quality assurance function to ensure compliance to the business plan, and customer satisfaction in terms of quality and quantity. Overall, effective MRM is an essential component of Operational Excellence along the value chain». [8, p.188].

Practical implementing of Macfarlane's works in some African MRM companies had shown that his proposed EMRM version as well as some competing ones encounter realization difficulties, in particular caused by companies' top managers fears with respect to innovations and their skeptic attitude to proposed MRM systems capabilities. In its turn, such negative attitude frequently happens to be justified due to lack of mechanisms to precisely and reliably evaluate economic effect obtained from MRM systems implementation.

South-African company Implats graphically demonstrates its work toward implementation of modern high-tech automated MRM system (Fig. 1). Whereas traditional organizational and technical MRM systems restrict their industrial activities to separate stages pertaining to geologic exploration, deposits development, and current MRs mining, Implats' MRM system in addition to this also comprehensively covers whole stages of deposits geological search, their thorough economic assessment, MRs refining and deep processing, products marketing and commercial realization, their dispatching and delivering, managing of company's assets, ecologic environment rehabilitation. High-tech MRM system designers especially stress that in addition to quantitatively assessable advantages it potentially facilitates such hard to evaluate positive effects as management streamlining concerning the processes of planning, modeling, activities results assessing; efficiency and informational procurement of decision making processes enhancing; collective knowledge base continuity and management enabling etc. As a result, management processes within the company are maintained at least at equivalent and often at higher than current industry level.

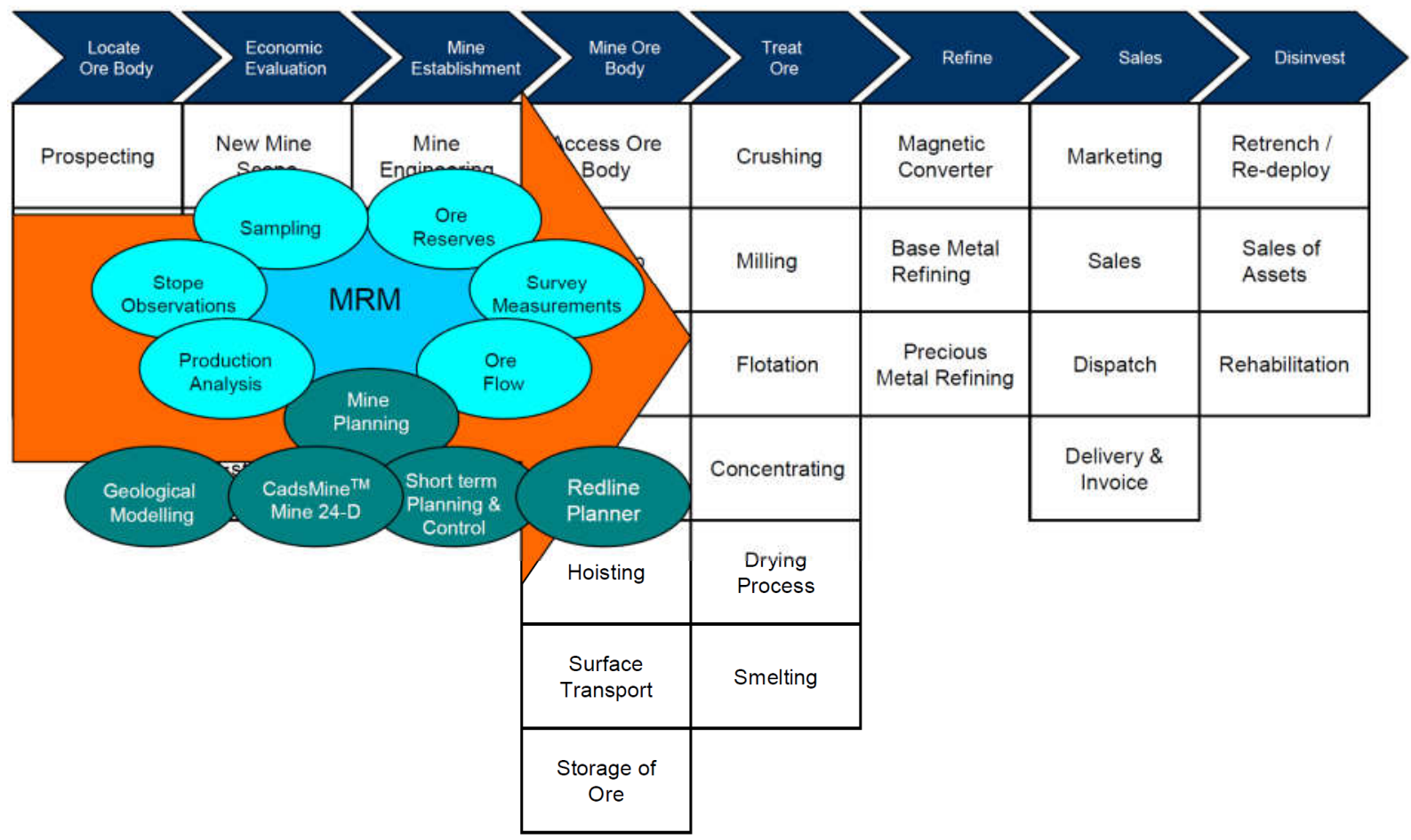

Figure 1 - Place of high-tech automated MRM-system in financially meaningful industrial and commercial operations practiced by Implats company [16]

In scientific, industrial, and advertising materials, prepared by companies or individual authors and distributed by various informational channels, beside above mentioned other definitions of MRM and corresponding activities are present. According to existing definitions and also companies' profile self-descriptions the most common MRM notion is the activities direction that provides to its subjects maximum commercial gains for themselves, expressed 
as a rule in increasing corporation financial profits and diminishing operational and other expenses. According to definition of so called Mineral Resources Throughput Management (MRTM), it «is a unique business concept based on process and functionality alignment aimed at achieving optimum throughput. The overall purpose of applying the concept and its associated disciplines is to maximize income and/or reduce costs. To reach MRTM targets, business knowledge and insight must be adjusted and it is required of the learner to view the business from a perspective different to the conventional mining approaches used in the past. This is done by using a throughput-based business analysis, identifying the main throughput drivers, (production and cost) quantifying the drivers and classifying those drivers according to the variability in physical conditions» [17].

As BMG Consulting Pty Ltd is evidencing, its work reorganization on the basis of implemented MRTM system following results were achieved [18]: 20\% plus EBIT and NPV improvements in more than $80 \%$ of cases; elevation of a mine's operating performance from below $50 \%$ of its design capacity to over $80 \%$; reduction of operating variability to below $10 \%$ from the $20 \%$ plus generally accepted by miners.

Next meaningful aspect after commercial effectiveness, associated with MRM concept, is lately becoming reduction of ecologic damages, imposed by MRM companies' industrial activities. Popularity is also widening related to those notions, according to which existing as well as being created MRM objects are supposed to achieve goals that proceed from much wider or, vice versa, highly specialized narrow economic and social needs that the same time play crucial roles in scientific, technical, and social progress. Among these goals, in particular, may be different risks reduction, functional stability boosting with respect to enterprises, companies, and other social institutions; maximal social affect achievement at municipal, regional, and national levels.

It's worthwhile to note that many of newly emerging aspects, associated with the MRM term contents, fully comply with its definitions formulated in $[12 ; 14-15 ; 19]$ and other early authors' publications.

MRM-objects' theoretic and applied models. Above mentioned MRM definitions may be viewed essentially as conceptual models of objects named by this term. Along with this there are sufficient numbers of attempts to illustrate MRM objects by schematic diagrams that depict inner functional and organizational structures as well as these objects connections with environment.

One of these research direction initiators was Rideout V.C. [20] that had offered in 1980 a structural scheme of social-economic-resource system at the regional or national levels, in which MRs and other natural resources management plays key role. At the same time MRM itself has no separate representation and is essentially dispersed all over the Rideout's scheme (Fig.2).

Great numbers of classification models and schemes, depicting various aspects of MRM objects being considered as various natural systems, were presented by Sekisov G.V. For example, (Fig. 3) illustrates one of the most informative and conceptually substantive author's models. Offered in 1992 model illustrates presumed future development of MRM organizational structure at macro-regional or national levels. During model's primary discussion, at which well known specialists in geology, MRs mining and processing, state and corporation management participated, disparities were convincingly demonstrated between the proposed MRM organizational structure, which supposed to be created on strict hierarchical subordination principles, and, on the other hand, common tendencies of globalizing World and developing in market direction Russian economies. Subsequent development of both these economies fully justified critical attitude toward this prognostic model.

At the same initial research period the institutional-and-functional MRM model at corporations' and adjacent organizational levels was developed (Fig. 4). After its first generally accessible publication in [15, p.38-40] this model repeatedly appeared in subsequent authors publications and was discussed at many scientific conferences, including foreign ones. In addition to other proofs this confirms validity and scientific significance of the model. 


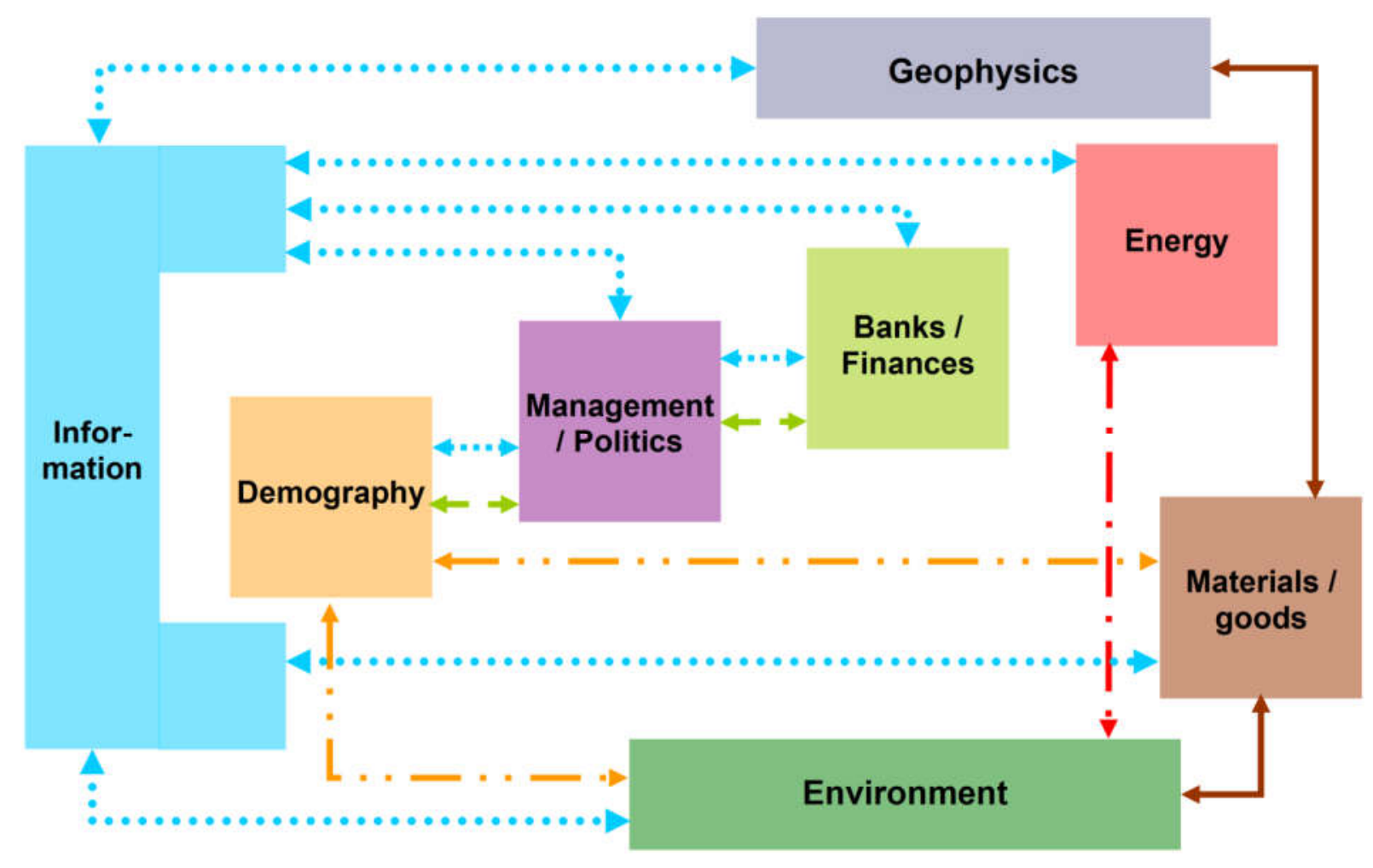

Figure 2 - Schematic diagram of a socio-economic natural resources management system at the regional or national levels [20]

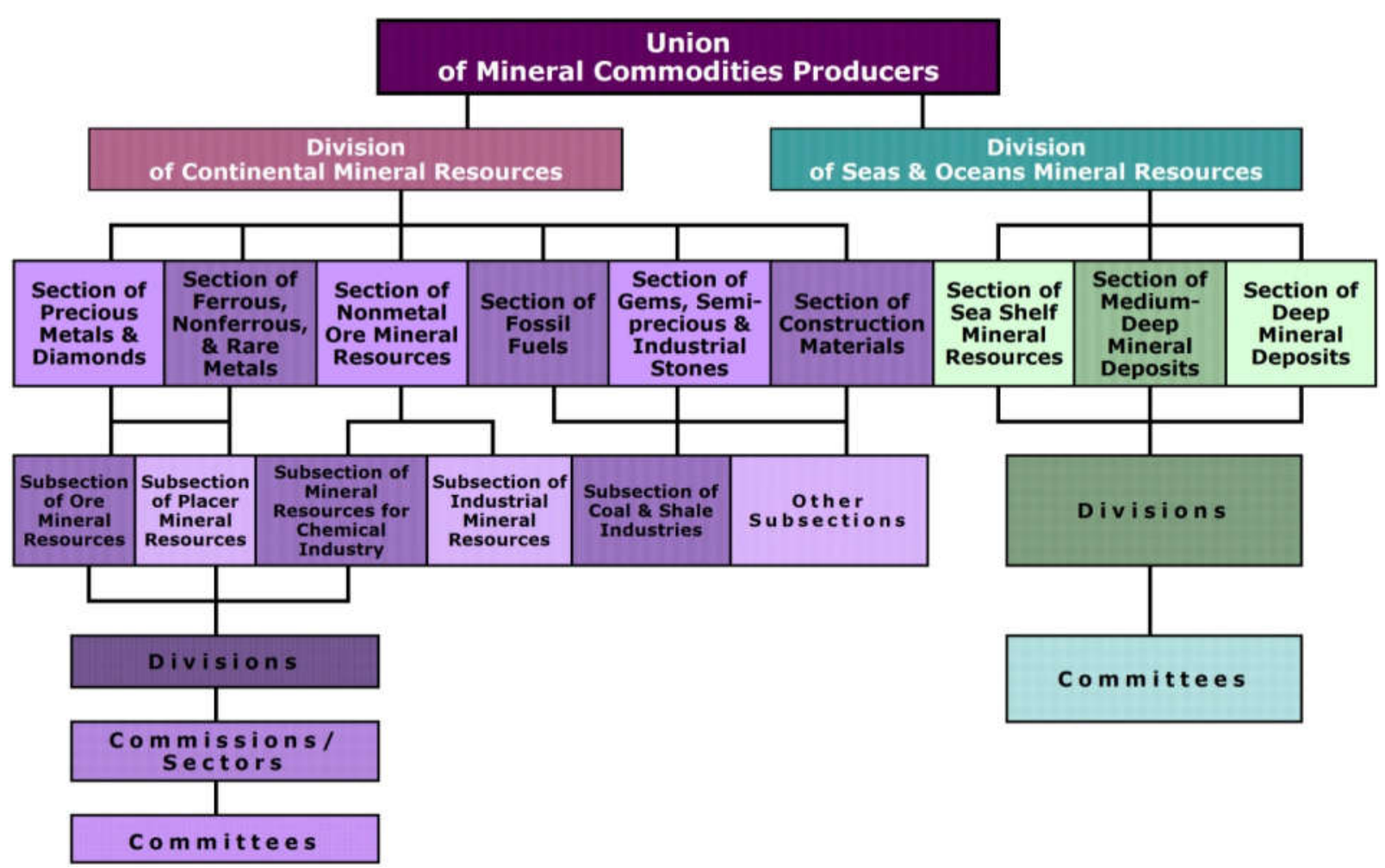

Figure 3 - Structure of the Minerals Producers' Union at macro-regional or national levels, forecast toward foreseeable future (Fragment, cited from [15, p.36]) 


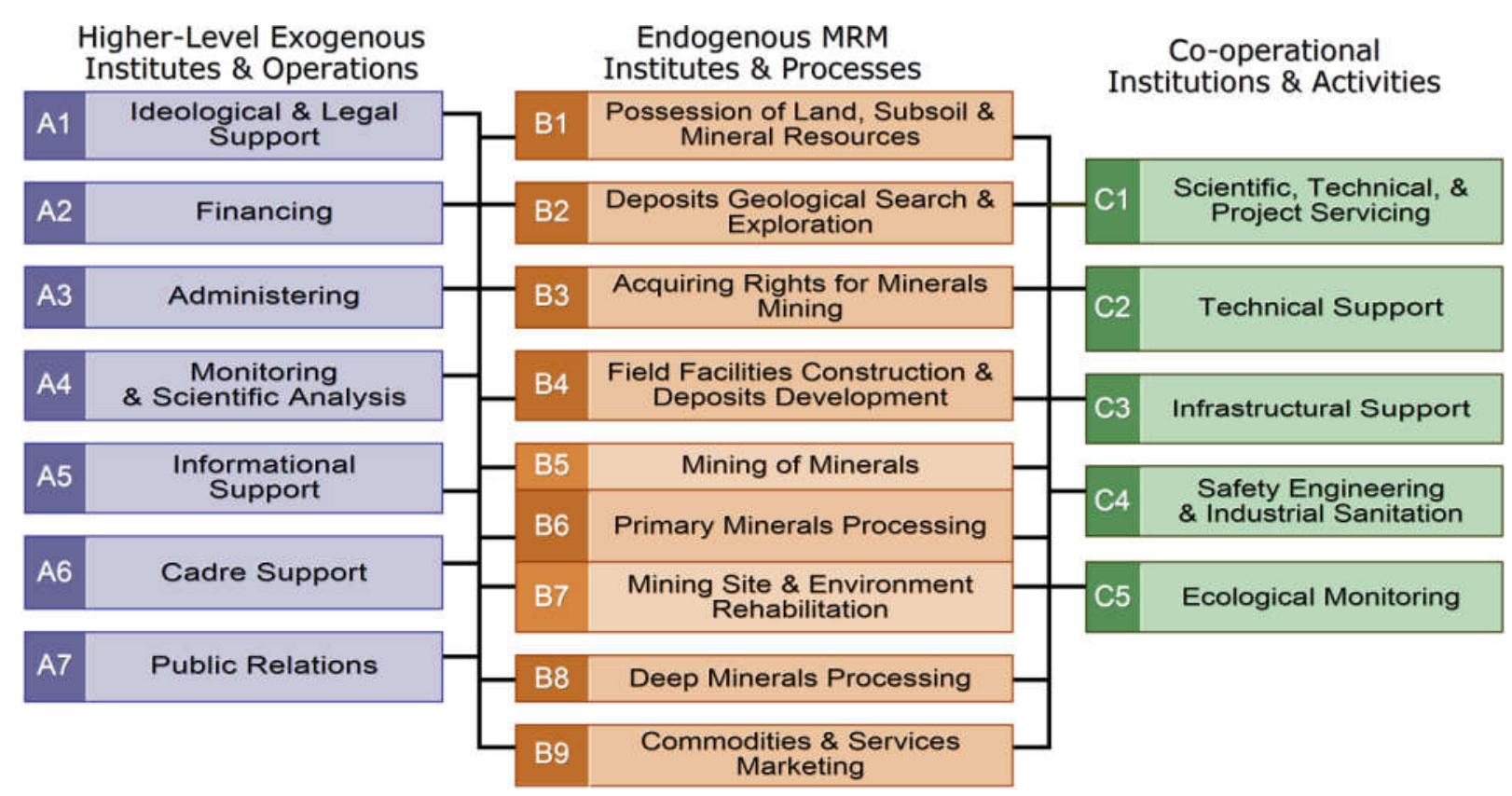

Figure 4 - Model of institutional-and-functional MRM structure at corporations' and adjacent organizational levels [15, p.38]

One of the model's virtues is its applicability both in planned and market economic conditions. In studies, carried out on this model basis, absence is demonstrated of discrete and, more than that, insurmountable boundaries between planned and market economic systems, realized in various countries engaged in MRM activities. By this a thesis was convincingly confirmed, which asserts that majority of modern national economies build themselves on hybrid models, using simultaneously plan and market management mechanisms presented in different combinations and realization forms. Accordingly, presentday countries' rigid subdivision into those having "planned» and «market» economic systems is proposed to be considered as essentially outdated. Instead of this abstract dichotomistic division, the scheme has been put forward that envisages MRM-countries classification into those adhering mostly to planned national economies management and, on the other hand, oriented predominantly at market management methods.

In addition to described above, various structural models that represent MRM objects of different sizes and hierarchical subordination, adapted to distinguished socio-economic conditions, have been offered by authors:

Russian - E. Galichanin, Yu. Dyachenko, V. Karaganov, E. Kozakov, E. Melekhin, B. Mikhailov, V. Nikitin, E. Porohnya, D. Sytenkov, V. Tararuyev, A. Shelomentsev et al.;

Foreign - U. Aswathanarayana, A. Barriskell, J. Camus, A. Macfarlane, R. Schmiermund et al.

\section{CONCLUSION}

The ongoing ideas and concepts development direction, aimed at natural resources management enhancing, rapidly widens, intensifies, and currently engulfs majority of agricultural and mineral-producing countries. Progress in this direction acts as stimulus for new Effective Natural Resources Management conceptions' varieties emergence as well as for improvement of existing ones.

Poland, Russia, other former USSR and Socialist Commonwealth successor countries are actively participating in these processes. In particular, since 1985 and up to now Poland is successfully publishing the only journal in the World, entirely devoted to Effective Mineral Resources Management problems and bearing corresponding title.

Russia, which has begun her full-scale market economic reforms in 1991, with respect 
to Mineral Resources Management ideas is characterized by prevailing outdated convictions that were inherent to plan-oriented stage of national economic development. At the same time there Universal and Institutional theoretic-and-applied Minerals Husbandry Conceptions have been proposed and during quarter of a century are being persistently developed, which enhance theory and accelerate EMRM ideas advancement into Russian and other countries' practice of natural resources effective management.

\section{REFERENCES}

1. Prilukov A.N. Cataloguing of economy's resource branches in rubricators and abstract databases // Russian Journal of Agricultural and Socio-Economic Sciences. 2017. No.1(61). P.39-52.

2. Radhakrishna B. Mineral resource management in developing countries. Report No.6. Association of Geoscientists for International Development. 1978. - URL: http://www.ischolar.in/index.php/JGSI/article/view/68951/59562

3. Hotelling $\mathrm{H}$. The economics of exhaustible resources // Journal of Political Economy. April, 1931. P. 137-175.

4. Socio-economic problems of mineral resources effective mining and utilization / Eds.: Astakhov A.S. and Tot M. - Moscow: Nedra, 1985. 275 p.

5. Prilukov A. Market potential of Russian and its Far Eastern Region mining industries // Proceedings of the 11-th International Multidisciplinary Scientific Geoconference SGEM2011. Bulgaria, Albena. 2011. V.1. P. 831-838.

6. Prilukov A. Peculiarities of mineral resources management systems in liberal and multistructural economies // Proceedings of the 11-th International Multidisciplinary Scientific Geoconference SGEM-2011. Bulgaria, Albena. 2011. V.1. P. 877-884.

7. Sekisov G.V., Prilukov A.N., Krupskaya L.T. Mineral sphere in the geospheres system // Regularities of the Structure and Evolution of Geospheres. Proceedings of the VII International Interdisciplinary Symposium. - Vladivostok: FEB RAS, 2005. P. 45-48.

8. Macfarlane A. Establishing a new metric for mineral resource management // The Journal of The South African Institute of Mining and Metallurgy. 2006. V. 106, P. 187198. - URL: http://www.saimm.co.za/Journal/v106n03p187.pdf

9. Prilukov A.N. Debating problems of the Russian mineral resource complex and innovative ways of their solving // Mineral Resources of Russia. Economics \& Management. 2014. No. 4. P. 64-71.

10. Litvintsev V.S., Prilukov A.N., Sekisov G.V. MRM scientific concept: emergence prerequisites and development stages // Mining Informational and Analytical Bulletin. 2015. Special Edition 30. P. 405-416.

11. Prilukov A.N. New insight into mineral resources management concept // ECO. 2008. No. 2(404). P. 45-62.

12. Sekisov G.V. Main problems of rational mineral resources management in modern conditions // Gornyi Zhurnal (Mining Journal). 1992. No. 1. P. 17-24.

13. Sekisov G.V. et al. Mineral resources management and main problems of its rationalizing // News of the Higher Institutions. Mining Journal. 2006. No. 4. P. 28-32.

14. Prilukov A.N. System concept of mineral resources utilization // Ecological problems of mining industry, minerals processing and wastes disposal. - Moscow. 1995. P. 324-328.

15. Prilukov A.N. Regional mineral resources management in market conditions. Vladivostok: Dalnauka, 1998. 156 p.

16. Acheampong E. Mineral resource management (MRM). 2004. - URL: http://www.implats.co.za/im/files/p/mineral_res_management_dec04.pdf

17. Westhuizen, W. Mineral Resource Throughput Management. Last updated: 29 November 2010. - URL: http://natagri.ufs.ac.za/content.aspx?uid=84

18. BMG Consulting Pty Ltd. - URL: http://bedrockmg.com/what-we-do

19. Sekisov G.V. Bases of mineral use. - Vladivostok: Dalnauka, 1998. 289 p.

20. Rideout V.C. Modeling studies of socio-economic-resource systems. Resources and development. - El-Shafie: Univ. of Wisconsin Press. 1980. P. 425-454. 